\title{
Cancelamentos e Ecologia
}

\section{Cancellations and Ecology}

Guilherme Reolon de Oliveira ${ }^{1}$

\section{Resumo}

Os “cancelamentos" nas redes sociais. São fortes os embates entre os que defendem a liberdade de expressão como direito fundamental e os que elevam o "lugar de fala" à categoria de superioridade, principalmente quando o assunto é relativo a questões identitárias e minoritárias. A polarização das redes deu contornos extremados a esse embate. A solução talvez passe pelo equilíbrio, pela temperança. Aristóteles, e mediedade, a virtude moral. Sartre, a liberdade com responsabilidade. $\mathrm{O}$ fundamento da sustentabilidade, cujo objetivo é a agregação, jamais qualquer tipo de exclusão. Já foi dito que as redes sociais tribalizam a cultura partilhada. Formamse "bolhas". O “cancelamento", ainda que motivado por questões ético-políticas, destrói mais sujeitos que ideias e é oposto à democracia. No lugar do "cancelamento", o acolhimento, a responsabilidade pelo Outro (e o respeito à sua singularidade), que não passa pela dimensão do dever, mas do reconhecimento do Rosto: ecosofia.

Palavras-chave: cancelamento, redes sociais, ecologia \& ética, reconhecimento, hospitalidade, equilíbrio, responsabilidade

\footnotetext{
Abstract

The "cancellations" on social networks. There are strong clashes between those who defend freedom of expression as a fundamental right and those who raise the "place

1 Jornalista (Mtb 15.241), sociólogo (Mtb 1.029), filósofo, curador de arte e crítico cultural. Doutorando em Filosofia (PUC-RS), Mestre em História, Teoria e Crítica de Arte (PPGAV/UFRGS), Mestre em Psicologia Social e Institucional (UFRGS), Bacharel em Filosofia (UFRGS/UCS), Bacharel em Ciências Sociais (UFRGS), Bacharel em Comunicação Social - Jornalismo (UCS). Coeditor do site apolineo.net. Autor de "Arte pós-nonsense, ou da dança como gênese do Ser da Arte" (EDUCS, 2019).

E-mail: guilhermereolon@terra.com.br
} 


\section{2 | Dossiê - Natureza e Sociedade no Antropoceno - Superando a Separação?}

of speech" to the category of superiority, especially when the subject is related to identity and minority issues. The polarization of the networks gave extreme contours to this clash. The solution may be balance, temperance. Aristotle, and mediation, the moral virtue. Sartre, freedom with responsibility. Such is the foundation of sustainability, whose objective is aggregation, never any kind of exclusion. It has already been said that social networks tribalize shared culture. "Bubbles" form. "Cancellation", although motivated by ethical-political issues, destroys more subjects than ideas and is opposed to democracy. In place of "cancellation", acceptance, responsibility for the Other (and respect for their uniqueness), which does not involve the dimension of duty, but the recognition of the Face: ecosophy.

Keywords: cancellation, social networks, ecology \& ethics, recognition, hospitality, balance, responsibility

Etimologicamente, ecologia é palavra que deriva das gregas oikos e logos. Oikos designa casa, ambiente, o que amplia a significação da ecologia: perpassa questões relativas à natureza. O filósofo e psicanalista Felix Guattari, atento a isso, destacara que são três os registros ecológicos: o do meio ambiente, o das relações sociais e o da subjetividade humana.

Parece-me importante, neste momento pandêmico, refletir não somente sobre o que fazemos com as árvores, as águas e os animais que nos cercam e convivem conosco, mas sobre nossas relações. É evidente o debate sobre os “cancelamentos" de pessoas - sim, porque, independentemente de suas ideias, são sujeitos - nas redes sociais. Destroem-se reputações, carreiras e subjetividades. São fortes os embates entre os que defendem a liberdade de expressão como direito fundamental absoluto e os que elevam o "lugar de fala" à categoria de superioridade, principalmente quando o assunto é relativo a questões identitárias e minoritárias.

Na polarização que foi exacerbada nos meios digitais, esse embate também ganhou contornos extremados. A solução, me parece, sempre passa pelo equilíbrio, pela temperança, o caminho do meio, como também nos legara Aristóteles, na Ética a Nicômaco. 


\section{Ecologia e ética}

\subsection{Da virtude moral: a mediedade como ápice}

Ethica Nicomachea é um dos quatro tratados de ética de Aristóteles, ao lado de Ethica Eudemia, Magna Moralia e De virtutibus et vitilis. É também a obra ética mais conhecida do pensador e a mais comentada desde a Antiguidade. O livro fora dedicado, com maior probabilidade, ao seu filho e, com menor probabilidade, ao seu pai.

A ética aristotélica está associada à noção grega de felicidade (eudaimonia) e, como tal, "certa atividade da alma segundo perfeita virtude". As virtudes, por sua vez, disposições dignas de elogios, se configuram em intelectuais (por ex. a sabedoria, a perspicácia, a prudência), adquiridas pelo ensino (em termos de experiência e tempo), e em morais (por ex. a generosidade e a temperança - que inclui a indignação, ou seja, diferente do 'acatamento'), adquiridas pelo hábito, alcançadas na prática, via convivência com a alteridade: primeiramente o Outro fundante do sujeito e, posterior à sua simbolização, o outro da socialização.

A virtude moral, ou a boa medida de nossas ações, por sua vez, é correlata à mediedade e à disposição do sujeito em escolher por deliberação. Ligada à felicidade e, também ao Bem (eis o objetivo da ação virtuosa), a ética aristotélica se contrapõe à ética dos prazeres (dos gozos $\left.{ }^{2}\right)$, contemporaneamente designada como utilitarismo, já que, antes, está associada à responsabilidade. Para Aristóteles, o prazer não é um bem: ele provém de natureza perversa (o que, logo, poderíamos traduzir, por gozo), seja de nascença, seja por efeito do hábito, como os "prazeres" dos homens viciosos3.

Felicidade, portanto, é agir bem. Não raras vezes, implica buscar o que é moralmente belo (o ethos) às custas do que não nos é vantajoso. O tratado nicomaqueio da virtude moral gira em torno da responsabilidade moral e da liberdade da ação - por isso é que, a seguir, o associarei à ética sartreana. A virtude

\footnotetext{
${ }^{2}$ Gozo difere de Prazer, segundo REOLON (2008), em sua leitura da psicanálise freudo-lacaniana. Segundo a autora, o Gozo vincula-se à estrutura perverso-paranóica e ao instinto de morte. O Prazer, à estrutura neurótica e suas manifestações (histeria e obsessão) e ligado ao instinto de vida.

3 "Como são três os objetos de busca e três os de fuga - o belo, o proveitoso e o agradável - e três os contrários - o feio, o danoso e o penoso -, o homem bom é correto e o homem perverso é incorreto a respeito de todos eles, mas sobretudo a respeito dos prazeres, pois este comum aos animais e acompanha a tudo o que cai na rubrica busca, pois o belo e o proveitoso são manifestamente prazerosos”. (ARISTÓTELES, 2008, p.45).
} 


\section{4 | Dossiê - Natureza e Sociedade no Antropoceno - Superando a Separação?}

moral, nesse sentido, é a mediedade (o equilíbrio, a harmonia) entre a falta e o excesso - lembremos do preceito délfico, "nada em excesso".

Para compreendermos como se configura a virtude moral, associada à noção de mediedade, e que é adquirida pelo hábito (logo por escolhas, e Aristóteles coloca aqui a expressão “escolha deliberada”), necessário se faz o entendimento da noção de deliberação. A virtude moral é uma disposição de escolher por deliberação, por isso a escolha deliberada encontra-se no cerne da noção de virtude moral. A escolha deliberada está, intimamente, ligada à responsabilidade do sujeito: não na adoção dos fins, mas antes na escolha dos meios ${ }^{4}$. Enquanto disposição, neste sentido, a deliberação está associada às tendências do caráter (também traduzível pela estruturação psíquica do sujeito): as intenções, as motivações do agente, o discernimento de reconhecer, nos particulares, o que é, de fato, bom.

A virtude aprimora o bom estado. Todo conhecedor, para Aristóteles, evita o excesso e a falta, e busca o meio termo. Por essência e pela fórmula que exprime equidade, a virtude é mediedade, mas segundo o melhor e o bem, é um ápice. É também neste sentido que nem toda ação admite mediedade: há ações que são vis por elas mesmas, não por seus excessos ou faltas. Para Aristóteles, entretanto, ações e reações tendem sempre ao equilíbrio, devem estar atentas à harmonia, de acordo com as circunstâncias: novamente, a moderação5.

Moderação implica, acrescento, uma ex-sistência e Olhar sobre o Outro de forma existencial, qual seja a do respeito, se o que se recebe é da ordem de uma límpida alteridade, e do limite, se há invasão, porque o Rosto, como muito sabiamente Levinas afirmara, é o começo da inteligibilidade - e, acrescentaria, da subjetividade (a mascarada, no oposto é a da ordem da dessimbolização, do asujeito). Não há sociedade na mascaração: há o espetáculo, que não passa de relação invertida, desumanização, repetição, aniquilamento da alteridade, negação da diferença e, consequentemente, da realidade que a sustenta.

O inter-humano propriamente dito está numa não-indiferença de uns para com outros, numa responsabilidade de uns para com os outros, mas antes que a reciprocidade desta responsabilidade, que se inscreverá nas leis

\footnotetext{
${ }^{4} \mathrm{Na}$ interpretação de Walter Benjamin do imperativo categórico de Kant: a ética está atenta ao humano sempre como fim, nunca como meio.

5 "Nem toda ação admite mediedade, tampouco toda emoção, pois algumas são denominadas em imediata conjunção com a vileza, como a malevolência, a impudicícia, a inveja e, quanto às ações, o adultério, o roubo, o assassinato. Com efeito, todas essas e as demais são censuradas por serem elas próprias vis e não por serem vis os seus excessos ou faltas. Não há jamais como acertar a seu respeito, mas sempre se erra". (ARISTÓTELES, 2008, p.52).
} 
impessoais, venha sobrepor-se ao altruísmo puro desta responsabilidade inscrita na posição ética do eu como eu; antes de todo contrato que significaria, precisamente, o momento da reciprocidade onde pode, com certeza, continuar, mas onde pode também atenuar-se ou extinguir-se o altruísmo e o des-interessamento. (LEVINAS, 2005, p. 141).

Bem é diferente de Bem aparente (ou o que é agradável). Ao homem virtuoso é objeto do querer o bem segundo a verdade. O virtuoso vê a verdade, esta se manifesta a ele, em cada coisa. A verdade, no entanto, às vezes se apresenta encoberta, "mascarada", há na troca virtuosa o alcançar a verdade (alethéia, desvelamento 6 , des-marcaramento).

Com efeito, o homem virtuoso julga corretamente cada coisa e em cada uma a verdade se manifesta a ele, pois há coisas belas e agradáveis a cada disposição e presumivelmente o homem virtuoso se distingue sobretudo pelo fato de ver o verdadeiro em cada coisa, como se fosse um padrão e uma medida delas. (ARISTÓTELES, 2008, p.70).

Está em nosso poder sermos bons ou maus, fazer ou não fazer. A maldade, neste sentido, é voluntária. Uma vez que nos tornamos injustos, ou seja, pelo hábito, não é mais possível não sê-lo. É por isso que são reprováveis os vícios que estão sob o nosso poder. Vícios e virtudes são voluntários. Diante disso, as virtudes morais são mediedades, são disposições por si mesmas (de distinguir entre o bem e o mal), estão em nosso poder, são voluntárias (ou seja, seus princípios estão no agente e o agente conhece as circunstâncias nas quais a ação ocorre) e são designadas tais quais a reta razão ordena.

Não obstante, a ética aristotélica é também uma ética da liberdade, já que fundada na possibilidade de dizer sim ou não em função da deliberação sobre os meios para realizar bons e belos fins. Não se trata de dizer que um ato moralmente bom é o que é feito por um agente moralmente bom: não se trata de agir conforme um imperativo categórico, mas antes a um ethos fundamental - a moralia (ao íntimo das deliberações familiares, de acordo com os preceitos ancestrais). $\mathrm{O}$ ato é moralmente bom porque responde a propriedades que o caracterizam como um meio termo em certas circunstâncias, apartado do excesso e da falta, que constituem ambos o vício.

\footnotetext{
6 “[...] a verdade não é desvelamento que destrói o mistério, mas antes uma revelação que lhe faz justiça" (BENJAMIN, 2013b, p.19).
} 
6 | Dossiê - Natureza e Sociedade no Antropoceno - Superando a Separação?

\subsection{Do existencialismo: não há liberdade sem responsabilidade}

Sartre, em O existencialismo é um humanismo (1987), inicia afirmando que o existencialismo é uma "doutrina que torna a vida humana possível e que, por outro lado, declara que toda verdade e toda ação implicam um meio e uma subjetividade humana" (p.3), cujo cerne está calcado na afirmação "a existência precede a essência, ou, se se preferir, que é necessário partir da subjetividade" (p.5). Compactuo com o autor: é necessário que partamos da subjetividade, do homem em si - e acrescentaria: não só do humano, mas de todo ser vivo -, para investigar qualquer questão que possamos pensar social: a sociedade é um conjunto, uma formação de seres individuais, portadores de subjetividades, logo existências singulares, únicas, não replicáveis. Cada ser é permeado por uma dignidade inviolável: o indivíduo, jamais replicável, é portador de um complexus, uma sacralidade, jamais escrava de Outrem.

Se unos, não passíveis de cópia, cada ente, cada sujeito, é responsável por suas ações. Sartre coloca que "quando dizemos que o homem é responsável por si mesmo, não queremos dizer que o homem é apenas responsável por sua estrita individualidade, mas que ele é responsável por todos os homens" (p.6). Se nos encaminhamos para uma nova condição subjetivo-social, há que se olhar (Olhar com escuta!) o Outro, esse que convive e vive conosco, esse que nos constitui e nos abarca, há que se avistar a ética, o âmago do ser, do ser-agir no social. É o que Sartre expõe como o sujeito legislador, que não escolheu apenas a si mesmo, mas, simultaneamente, a humanidade inteira. Levinas acrescenta que Outrem é aquele por quem sou responsável e que essa responsabilidade só acontece pelo encontro, que é o inverso da aniquilação ou da contaminação de unicidades.

\footnotetext{
O encontro com Outrem é imediatamente minha responsabilidade com ele [...] é sempre a partir do Rosto, a partir da responsabilidade por Outrem, que aparece a justiça, que comporta julgamento e comparação, comparação daquilo que, em princípio, é incomparável, pois cada ser é único; todo outrem é único. (LEVINAS, 2005, p. 143-144).
}

Esse ente "não consegue escapar ao sentimento de sua total e profunda responsabilidade" (SARTRE, 1987, p.7), pois qualquer projeto (tal qual o da condição que investigamos) "por mais individual que seja, tem um valor universal" (p.10). Como nos lembra Levinas: minha liberdade começa quando começa a liberdade do Outro. Ressaltemos, a sacralidade do indivíduo é anterior a qualquer 
social: a dignidade humana, o valor humano consiste na subjetividade, no que cada sujeito porta de singularidade e diferença: não há possibilidade de social sem a liberdade - e ressaltamos, a responsabilidade - de cada qual.

Destaca o pensador que "não há determinismo, o homem é livre, o homem é liberdade" (p.5), então somos o uno único, inscrito num âmago individual-social, portanto que não pode conceber a não-liberdade da humanidade inteira. Se assim o procedemos, não há como escapar da ética, filosofia primeira. Há uma imensidão conosco, há um inteiro em cada um de nós, sempre faltante7, sempre em busca de algo, logo há uma impossibilidade da solidão, somos um feixe de relações, há uma intersubjetividade. Se há, e há, não escapamos da responsabilidade integral por cada escolha. Caso contrário, nasce a anti-sociedade, a anti-polis. Não há liberdade quando um único ser é escravo - ou mesmo senhor. O humano é livre quando inscrito em um ethos digno de existência: o ethos da responsabilidade. Não concebemos social sem a existência livre de cada ser, sem a total liberdade - de escolha, de opinião e de existência - de cada indivíduo: "[...] nós nos apreendemos a nós mesmos perante o outro, e o outro é tão verdadeiro para nós quanto nós mesmos [...] Para que eu obtenha qualquer verdade sobre mim, é necessário que eu considere o outro" (p.16).

\section{Contra o cancelamento: acolhimento e hospitalidade}

A responsabilidade pelo Outro e o equilíbrio (no que se refere à moralidade) são os fundamentos da sustentabilidade, cujo objetivo é a agregação, jamais qualquer tipo de exclusão. Pensar a ecologia na atualidade, obviamente passa pela preocupação com o que acontece na Amazônia e no Pantanal, mas não só. Com a mineração em terras indígenas, mas não só. Com as podas e derrubadas de nossas árvores, nas cidades, mas não só. Lembro-me de um desenho de minha infância, Capitão Planeta, em que o herói era constituído pela união dos elementos naturais (materiais) com os emocionais (as relações, os sujeitos). Isso é comunidade!

Já foi dito que as redes sociais tribalizam a cultura partilhada, ou seja,

\footnotetext{
7 "Se a ação de cada um não está mais referida ao que a ultrapassa e a garante, não há mais diferença entre o direito à liberdade de que cada um dispõe doravante incondicionalmente e o abuso do direito à liberdade" (DUFOUR, 2005, p.97).
} 


\section{8 | Dossiê - Natureza e Sociedade no Antropoceno - Superando a Separação?}

juntamo-nos cada vez mais, aos nossos semelhantes ${ }^{8}$ (nem tanto!), não àqueles diferentes. Formam-se gangues ${ }^{9}$, bolhas.

A mídia, de fato, é uma das forças subentendidas na formidável dinâmica de individualização dos modos de vida e dos comportamentos da nossa época. A imprensa, o cinema, a publicidade e a televisão disseminaram no corpo social as normas da felicidade e do consumo privados, da liberdade individual, do lazer e das viagens e do prazer erótico: a realização íntima e a satisfação individual tornaram-se ideais de massa exaustivamente valorizados. (LIPOVETSKY, 2004, p. 70)

Mas as pesquisas indicam que elas, as redes sociais, estão em declínio. O "cancelamento" ainda que motivado por questões ético-políticas destrói mais sujeitos que ideias e é o oposto à democracia. Respeitar o outro em sua singularidade, independentemente de suas características (ou por elas e apesar delas), demonstra que o politicamente correto é a pior censura.

Entendemos, com Levinas, que ética é a própria relação com a alteridade de Outrem, que só se efetiva na cultura (a responsabilidade por Outrem), e na valorização do Rosto (semblante), a linguagem antes das palavras. Antes do Rosto, o Olhar que deseja e constitui Desejo, Sujeito, dá base para que a lei seja inscrita. É por meio do Olhar, no Olhar - no entre-Olhares - que há o reconhecimento do Outro. O Mesmo acontece pelo Olhar, e o Olhar é que permite mais que o ver, o Reconhecer - princípio primeiro da Ética.

O Mesmo, sua identidade e sua diferença, revelado no Olhar e no Rosto que porta, também está inscrito numa marca, num traço, no nome próprio, advindo, inclusive, do Outro. "Um nome próprio não é nunca puramente individual", afirmara Jacques Derrida (2003, p.23), já que nele o sujeito carrega sua estrutura, sua unicidade e sua multiplicidade, que, tal qual o nome (inviolável e intransferível),

\footnotetext{
8 "Do mesmo modo que Narciso, o personagem da mitologia grega, apaixonou-se por sua própria imagem numa lagoa, os indivíduos do capitalismo contemporâneo também precisam de um espelho em que possam recobrar o amor por sua própria imagem, tão comprometido pelo esforço de continuar a gerar valores financeiros. É por causa disso que Adorno diz que a cultura de massa como um todo é narcisista, pois ela vende a seus consumidores a satisfação manipulada de se sentirem representados nas telas do cinema e da televisão, nas músicas e nos vários espetáculos" (FREITAS, 2003, p.19).

${ }^{9}$ Segundo Mike Featherstone (1995), o pós-modernismo é caracterizado pela transformação da realidade em imagens e pela fragmentação do tempo numa série de presentes perpétuos. Esta segunda característica tem como paradigma a esquizofrenia, considerada um colapso da relação entre os significantes, o colapso da temporalidade, memória, senso de história. A experiência imediata e indiferenciada da presencialidade do mundo, para o esquizofrênico, conduz a uma noção de "intensidades".
} 
só a história do sujeito comporta e alicerça - seu passado, seu presente e mesmo seu futuro.

O filósofo da desconstrução (que nunca é o que alguns associam à destruição mas, pelo contrário, à absoluta construção de algo, "destrinchamento") destaca que, no acolhimento, a ética interrompe a tradição filosófica do parto e desfaz a astúcia do mestre quando este finge desaparecer atrás da figura da parteira. Uma política de hospitalidade é uma política do poder quanto ao hóspede, quer seja ele o que acolhe ou o acolhido. Para Levinas, o acolhimento dá e recebe outra coisa, mais do que eu e mais que outra coisa:

\begin{abstract}
Desde as primeiras páginas de Totalidade e infinito, lê-se que abordar o Outro no discurso é acolher sua expressão em que ele ultrapassa a todo instante a ideia que se poderia ter dele. É então receber do Outro para além da capacidade do eu; o que significa exatamente: ter a ideia do infinito. Porém isso significa também ser ensinado. A relação com o Outro ou o Discurso é uma relação não-alérgica, uma relação ética, porém esse discurso acolhido é um ensinamento. Porém o ensinamento não retorna à maiêutica. Ele vem do exterior e me traz mais do que eu contenho. (DERRIDA, 2004, p.35-35).
\end{abstract}

Esse receber, proposto como sinônimo de acolher por Derrida, só recebe na medida - uma medida desmedida - em que ele recebe para além da capacidade do eu. Essa desproporção dissimétrica marca a lei da hospitalidade. A palavra "acolher" designa, com a noção de Rosto, a abertura do eu, e a anterioridade filosófica do sendo sobre o ser. O Discurso, assim, se apresenta como Justiça "na retidão do acolhimento dado ao rosto" (DERRIDA, 2004, p.46).

A hospitalidade, para Derrida (2004), é a essância (diferente de essência) do que é ou, antes, do que se abre assim para além do ser. Numa continuidade do pensamento levinasiano, a hospitalidade é infinita ou ela não é; ela é acordada ao acolhimento da ideia do infinito, portanto do incondicional, e é a partir de sua abertura que se pode dizer, como o fará Levinas, que a ética não é uma disciplina da filosofia, mas a "filosofia primeira".

Já nos aconteceu de perguntarmo-nos se a hospitalidade absoluta, hiperbólica, incondicional, não consistiria em suspender a linguagem, uma certa linguagem determinada, e mesmo o endereçamento ao outro. Sendo assim, não seria preciso submeter a uma espécie de contenção essa tentação de perguntar ao outro quem ele é, qual é o seu nome, de onde ele vem, etc? Não seria preciso abster-se de colocar essas questões que anunciam um tal número de condições requeridas, portanto limites a uma hospitalidade assim constrangida e confinada num direito e num dever? (DERRIDA, 2003, p.117). 
10 | Dossiê - Natureza e Sociedade no Antropoceno - Superando a Separação?

No lugar do "cancelamento", o acolhimento, a responsabilidade pelo outro, que não passa pela dimensão do dever, da obrigação, mas do reconhecimento, do respeito de si. O respeito ao outro indica respeito e ética consigo mesmo e com os seus (verdadeiro sentido da ética mesma).

\section{Referências}

BENJAMIN, Walter. A obra de arte na época de sua reprodutibilidade técnica. In: LIMA, Luiz Costa. Teoria da cultura de massa. 5 ed. São Paulo: Paz e Terra, 2000.

BENJAMIN, Walter. A ética - Fragmentos (filosofia da história e política). In: O anjo da história. 2 ed. Belo Horizonte: Autêntica, 2013 a.

BENJAMIN, Walter. Eduard Fuchs, colecionador e historiador. In: O anjo da história. 2 ed. Belo Horizonte: Autêntica, 2013a.

BENJAMIN, Walter. Origem do drama trágico alemão. 2 ed. Belo Horizonte: Autêntica, 2013b.

BENJAMIN, Walter. Sobre o conceito de história. In: O anjo da história. 2 ed. Belo Horizonte: Autêntica, 2013a.

CREMASCHI, Sergio. Tendências neoaristotélicas na ética atual. In: OLIVEIRA, Manfredo A. (org.). Correntes fundamentais da ética contemporânea. 2 ed. Petrópolis: Vozes, 2001.

DEBORD, Guy. A sociedade do espetáculo. Rio de Janeiro: Contraponto, 1997.

DERRIDA, Jacques. Posições. Belo Horizonte: Autêntica, 2001.

DERRIDA, Jacques. A palavra acolhimento. In: Adeus a Emmanuel Levinas. São Paulo: Perspectiva, 2004.

DERRIDA, Jacques. Da hospitalidade. São Paulo: Escuta, 2003.

DUFOUR, Dany-Robert. A arte de reduzir as cabeças: sobre a nova servidão na sociedade ultraliberal. Rio de Janeiro: Companhia de Freud, 2005.

FEATHERSTONE, Mike. Cultura de consumo e pós-modernismo. São Paulo: Studio Nobel, 1995.

FREITAS, Verlaine. Adorno \& a arte contemporânea. Rio de Janeiro: Zahar, 2003.

GUATTATI, Félix. As três ecologias. 21 ed. Campinas: Papirus, 2012.

LEVINAS, Emmanuel. De l'existence à l'existant. Paris: Vrin, 1986. 
LEVINAS, Emmanuel. Totalidade e infinito. Lisboa: 70, 1988.

LEVINAS, Emmanuel. Entre nós: ensaios sobre a alteridade. Petrópolis: Vozes, 1997.

LEVINAS, Emmanuel. La realité et son ombre. In: Les Temps Modernes, n. 38, nov. 1948, p.771-789.

LEVINAS, Emmanuel. De l'oblitération. Paris: Editions de la différence, 1990.

LIPOVETSKY, Gilles. A era do vazio. Lisboa: Relógio D'Água, 1989.

LEVINAS, Emmanuel. Crepúsculo do dever: a ética indolor dos novos tempos democráticos. 3 ed. Lisboa: Dom Quixote, 2004.

LEVINAS, Emmanuel. Metamorfoses da cultura liberal: ética, mídia, empresa. São Paulo: Sulina, 2004.

LEVINAS, Emmanuel. Os tempos hipermodernos. São Paulo: Barcarolla, 2004.

REOLON, Vera Marta. mulheres para um homem... para O Homem, A Mulher. Porto Alegre: Edipucrs, 2008.

SARTRE, Jean-Paul. A idade da razão. São Paulo: Instituto Progresso Editorial, 1949 .

SARTRE, Jean-Paul. A imaginação. Porto Alegre: L\&PM, 2011.

SARTRE, Jean-Paul. O existencialismo é um humanismo. São Paulo: Nova Cultural, 1987. (Coleção Os Pensadores)

ZINGANO, Marco. Aristóteles: tratado da virtude moral: Ethica Nicomachea I 13 - III 8. São Paulo: Odysseus, 2008.

Recebido em: 02/12/2020. Aprovado em: 11/12/2020. Publicado em: 26/12/2020. 